\title{
Conversion of 3A Zeolite from Bagasse Ash and Aluminium Hydroxide Sludge
}

\author{
[Rewadee Anuwattana, Worapong Pattayawan and Pattamaphorn Phungngamphan]
}

\begin{abstract}
This work aim to synthesis of a 3A zeolite (K-LTA) obtained by a fusion process of potassium salt, synthesized from the bagasse ash. The bagasse ash and aluminium hydroxide sludge were sources of starting materials for $\mathrm{K}$-A zeolite $(3 \mathrm{~A}$ zeolite) conversion using the alkali fusion hydrothermal process. The bagasse ash and potassium salt were mixed at the weight ratio of 1:1.2 and then fused at $550{ }^{\circ} \mathrm{C}$ for 1 hour prior to the hydrothermal treatment. After that, the hydroxide solution was added to the fused material slurry and thoroughly stirred at $105 \pm 3{ }^{\circ} \mathrm{C}$ in the stainless steel reactor. The reaction time was varied from 1 to 6 hours. The results showed that the highest yield of $3 \mathrm{~A}$ zeolite conversion was approximately $62 \%$ and was obtained from the mixtures containing hydroxide solution, stirred for 5 hours.
\end{abstract}

Keywords-3A zeolite, Bagasse Ash, Aluminium Hydroxide Sludge, Fusion Method, Waste Utilization

\section{Introduction}

Sugar industries and Pulp industries produce a large amount of sugarcane bagasse ash and it is burned to produce energy for boiler. Bagasse ash was also considered as the industrial waste containing siliceous. Sugarcane bagasse ash is a byproduct of sugar factories which is burnt to generate power for different activities in factory. The burning of sugar bagasse causes bagasse ash as a waste, which would be used as a cement replacement materials. It has been known that the total production of sugarcane is over 1,500 million tons. Literatures showed that there is about 300,000 tons of sugar production. The composition of sugarcane is $30 \%$ bagasse is recovered, about $10 \%$ and about $8 \%$ bagasse ash for boiler. The higher silica amount in the bagasse ash was suggested for soil improvements. One possible and effective alternative is to convert the bagasse ash into silicon source for alternative adsorbent for the removal of aqueous phase pollutants such as zeolties. It was used as an alternative source of silica to synthesis mordenite by Bajpal and Rao [1-3], Na-X zeolite by Dalal and Rao [4], zeolite $\mathrm{Y}$ by Hamdan and Keat [5], $\beta$-Zeolite by Didik [6] and ZSM-5 zeolite by W. Panpa [7].

Rewadee Anuwattana, Worapong Pattayawan, and Pattamaphorn Phungngamphan

Expert Centre of Innovative Clean Energy and Environment, Thailand Institute of Scientific and Technological Research Thailand.
In the aluminum industries, large quantities of residues in the form of sludge and liquid effluent are by products from cleaning operations. The large volume of waste products, leads to an increasing cost for their disposal, especially when considering that this sector, in general, is comprised of smalland medium-size companies. These operations employ sodium hydroxide solution. It can dissolve the aluminum surface to form sodium aluminate. Elimination of the residue is necessary. These wastes create a very serious waste disposal problem. Alumina from sludge is added in the precursor to obtain the desired $\mathrm{SiO}_{2} / \mathrm{Al}_{2} \mathrm{O}_{3}$ molar ratio.

Zeolite is a group of over 40 crystalline hydrated alumino silicate minerals with structures based on a three-dimensional network. Zeolites have a widespread application in ion exchange, molecular sieve and adsorption due to their structural characteristics and valuable properties. Conversion of fly ash into zeolites has become an important issue of waste management in recent years [8]. The common method used for zeolites synthesizing from fly ash involves a hydrothermal process, where fly ash is mixed with alkali solution at the required condition [9-11]. However, by introducing alkaline fusion stage prior to the conventional zeolite synthesis. This method can obtain single-phase and high crystalline zeolite such as zeolite $\mathrm{X}$ [12] who presented a two-stage method that enables synthesizing pure form of zeolite $\mathrm{A}$ and $\mathrm{X}$ and different type of zeolite [13-14]. The new development in zeolite synthesis from slag [15-16]. Ethanol dehydration by adsorption requires because of less energy than conventional azeotropic distillation. Various techniques have been developed to break the azeotrope of ethanol and water for anhydrous ethanol process. Bioethanol purification process after the fermentation process was in two stages, distillation and dehydration stages.

Adsorpbents for drying liquids, such as activated alumina, silica gel, and molecular sieves. Silica gel and activated alumina have large pore in the range of 100 to $500 \mathrm{~nm}$. Molecular sieve such as $3 \mathrm{~A}, 4 \mathrm{~A}$ and $5 \mathrm{~A}$ are $0.3,0.4$ and $0.5 \mathrm{~nm}$. Water and ethanol molecules with molecular diameter of 0.28 and $0.44 \mathrm{~nm}$, respectively. 3A zeolite can be used dehydration of polar liquids such as the mixture water-ethanol [17].

The purpose of this study was to synthesize $3 \mathrm{~A}$ zeolite from bagasse ash using aluminum sludge for dewatering in ethanol process. Development of this process will reduce the amount of waste being produced and will thus be an environmental benefit for no additional economic cost. The synthesis products were characterized by X-ray diffraction 
(XRD), X-ray fluorescence (XRF), scanning electron microscopy (SEM).

\section{Methodology}

The raw material for this work was the bagasse ash, which was obtained from Northern Thailand. Bagasse ash was collected from Environmental Pulp and Paper in Nakorn Sawan Province consisted of $90.3 \mathrm{wt} \% \mathrm{SiO}_{2}, 2.9 \mathrm{wt} \% \mathrm{Al}_{2} \mathrm{O}_{3}$, $3.1 \mathrm{wt} \% \mathrm{CaO}$ and $1.39 \mathrm{wt} \% \mathrm{~K}_{2} \mathrm{O}$. The pretreatment of the bagasse ash consisted of mechanical, acid and thermal treatments. Ashes were milled to particle size smaller than $0.05 \mathrm{~mm}$. After that, $10 \mathrm{~g}$ of the ash was digested with $3 \mathrm{M}$ $\mathrm{HCl}$ solution $(50 \mathrm{ml})$ at $100{ }^{\circ} \mathrm{C}$ for $1 \mathrm{~h}$. Finally, the thermal treatment, the ashes were calcined at $700{ }^{\circ} \mathrm{C}$ for $3 \mathrm{~h}$ to remove the incorporated organic matter. The chemical compositions of the ashes before and after the pretreatment were determined by X-ray Fluorescence (XRFS).

Aluminium sludge obtained from the wastewater plant of the Muang Tong aluminium factory, Thailand, was purified by etching with 0.01 molar sulfuric acid for $10 \mathrm{~min}$. The purified aluminum sludge was separated from the solution by vacuum filtration, washed with deionized water, dried in an aircirculating laboratory oven at $105^{\circ} \mathrm{C}$ for $5 \mathrm{~h}$ and cooled-down in a desiccator over dry silicagel before use. Chemical composition of the purified aluminum sludge (see Table 1) was determined by XRF. The aluminum sludge was stirred with $50 \% \mathrm{NaOH}$ to prepare the sodium aluminate solution.

A homogenous fusion mixture was prepared by grinding and mixing of bagasse ash: potassium salt in the ratio of 1:1.2. This mixture was heated at $550{ }^{\circ} \mathrm{C}$ for $1 \mathrm{~h}$. The resultant fused mass was cooled, milled and mixed in distilled water to form potassium silicate solution, with the addition of sodium aluminate. The solution were then mixed in a Teflon ${ }^{\mathrm{TM}}$-bottle followed by stirring for $20 \mathrm{~min}$ and then subjected to crystallization. The slurry was then subjected to aging and heat at $105 \pm 3{ }^{\circ} \mathrm{C}$ for $1-6 \mathrm{~h}$ in $23 \mathrm{~mL}$ Teflon ${ }^{\mathrm{TM}}$-lined stainless steel autoclave. The solid crystalline product was washed until $\mathrm{pH}$ was 8 and dried at a temperature of $105 \pm 3{ }^{\circ} \mathrm{C}$ for $24 \mathrm{~h}$ and after cooling-down was analyzed by XRD with vertical goniometer and graphite monochromated $\mathrm{CuK} \alpha$ radiation. The $3 \mathrm{~A}$ zeolite standard was scanned for 2-theta in the range 5 to $50{ }^{\circ} \mathrm{C}$. The d-spacing values of zeolite A to identify and quantify the crystalline phases. $(11.99,8.58,7.01,4.07,3.68$, $3.39,3.26,2.73,2.60)$ The corresponding XRD were recorded on a Bruker 11000. The external standard method was used for the determination of the weight fraction of the amorphous and crystalline phases and SEM. The zeolite phase and the relative amount of 3A zeolites were studied by X-ray diffraction.

Ethanol used in this work was of $40 \% \mathrm{v} / \mathrm{v}$ (fermentation juice) to increase the concentration of ethanol, The sample of zeolite $3 \mathrm{~A}$ standard and zeolite $3 \mathrm{~A}$ from bagasse ash were used in sorption experiments. Zeolite $3 \mathrm{~A}$ standard and zeolite $3 \mathrm{~A}$ from bagasse ash are widely employed in separating waterethanol mixture. The adsorbents were oven dried at $105{ }^{\circ} \mathrm{C}$ for $24 \mathrm{hr}$, to removal of humidity within the crystals of zeolite $3 \mathrm{~A}$. The dried zeolite $3 \mathrm{~A}$ standard and zeolite $3 \mathrm{~A}$ of bagasse ash were kept in bottles, then stored in a glass chamber. WaterEthanol azeotrope concentration was analyzed for its initial alcohol concentration then samples were examined for its weight determination. The $3 \mathrm{~A}$ zeolite $(5,10,15,20$ and $30 \mathrm{~g})$ were soaked in $50 \mathrm{~mL}$ of water-ethanol azeotrope in container for 60 minutes, the samples were stirred on a mechanical shaker. The sample was filtered and separated. To determine the water uptake of in zeolite $3 \mathrm{~A}$ standard and zeolite $3 \mathrm{~A}$ from bagasse ash, the weight difference of solution before and after soaking and also the initial and final alcohol concentration was investigated.

\section{Results and Discussion}

The raw bagasse ash is rich in $\mathrm{SiO}_{2}$, whereas $\mathrm{Al}_{2} \mathrm{O}_{3}$ content is small. The chemical composition has shown as Table 1. The $\mathrm{SiO}_{2} / \mathrm{Al}_{2} \mathrm{O}_{3}$ molar ratios of bagasse ash is 40.1. Quartz is the major crystalline phase in bagasse ash. There was a need to add $\mathrm{Al}_{2} \mathrm{O}_{3}$ in the reaction mixture to obtain the desired $\mathrm{SiO}_{2} / \mathrm{Al}_{2} \mathrm{O}_{3}$ molar ratio. The sample was synthesized by fusing bagasse ash with potassium salts for $3 \mathrm{~A}$ zeolite synthesis.

\section{TABLE 1. CHEMICAL COMPOSITION OF THE BAGASSE ASH AND ALUMINUM SLUDGE.}

\begin{tabular}{|c|c|c|}
\hline \multirow{2}{*}{ Chemical composition } & \multicolumn{2}{|c|}{ (\% wt) } \\
\cline { 2 - 3 } & Raw Bagasse Ash (S2) & Aluminum Sludge \\
\hline $\mathrm{SiO}_{2}$ & 90.3 & - \\
$\mathrm{Al}_{2} \mathrm{O}_{3}$ & 2.90 & 68.8 \\
$\mathrm{CaO}$ & 3.14 & 0.02 \\
$\mathrm{~K}_{2} \mathrm{O}$ & 1.39 & - \\
$\mathrm{Na}_{2} \mathrm{O}$ & 0.18 & 18.06 \\
$\mathrm{SO}_{3}$ & 0.72 & 0.01 \\
$\mathrm{Fe}_{2} \mathrm{O}_{3}$ & 0.16 & 0.06 \\
$\mathrm{CuO}$ & 0.15 & 0.02 \\
$\mathrm{other}^{2}$ & 1.06 & 13.03 \\
\hline $\mathrm{ThO}_{2} / \mathrm{Al}_{2} \mathrm{O}_{3}$ & 40.1 & - \\
$\mathrm{molar}^{\mathrm{ratio}}$ & & \\
\hline
\end{tabular}
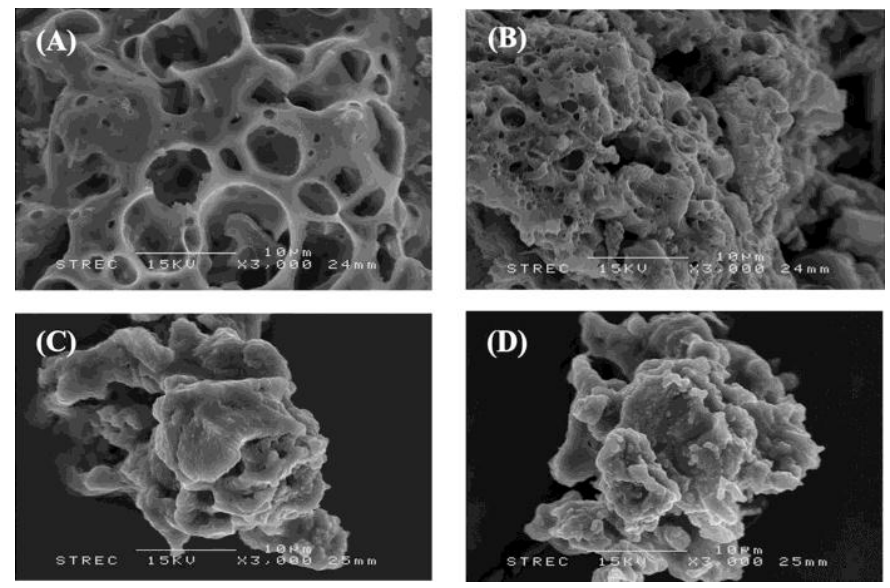

Figure 1 Scanning electron microscope (SEM) of raw bagasse ash residue (A), acid digestion bagasse ash (B), fusion bagasse ash with potassium salts in the weight ratio of $1: 1(\mathrm{C})$ and $1: 1.2(\mathrm{D})$ at $550^{\circ} \mathrm{C}$ for $1 \mathrm{hr}$. 
The morphology of bagasse ash (A), acid digestion bagasse ash (B), fusion bagasse ash with potassium salts in the weight ratio of $1: 1(\mathrm{C})$ and $1: 1.2(\mathrm{D})$ at $550^{\circ} \mathrm{C}$ for $1 \mathrm{hr}$ were taken using scanning electron microscope (SEM) in the 3,000 of magnitude as shown in Figure 1.

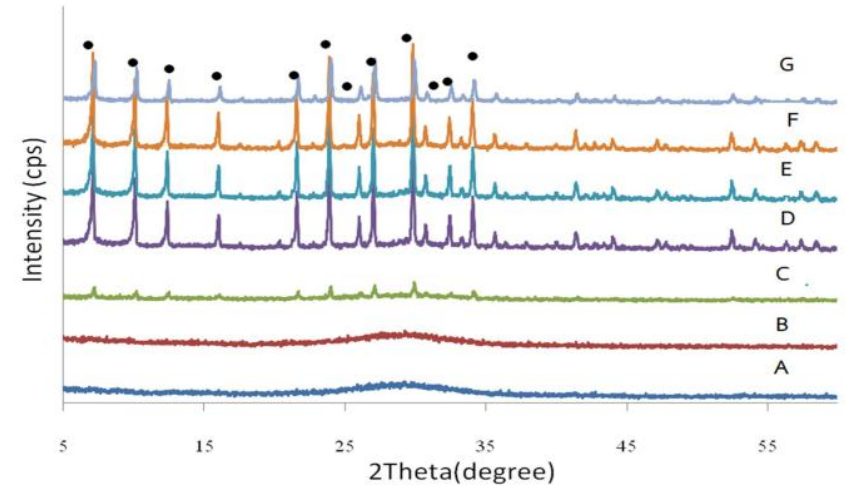

Figure $2 \mathrm{X}$-Ray Diffraction (XRD) of fusion bagasse ash with potassium salts in the weight ratio of $1: 1.2$ at $550^{\circ} \mathrm{C}$ for $1 \mathrm{hr}(\mathrm{A}), 2 \mathrm{hr}(\mathrm{B}), 3 \mathrm{hr}(\mathrm{C}), 4 \mathrm{hr}(\mathrm{D})$, $5 \mathrm{hr}(\mathrm{E}), 6 \mathrm{hr}(\mathrm{F})$ and 3A Zeolite Standard (G).

- Peak position of 3A Zeolite.

However, 3A zeolite crystallinity increased with increasing time after $2 \mathrm{~h}$, and then the diffraction intensities of $3 \mathrm{~A}$ zeolite increased to the optimum value in about $5 \mathrm{~h}$ of the reaction time from the mixtures containing hydroxide solution. The results showed that the highest yield of $3 \mathrm{~A}$ zeolite conversion was approximately $62 \%$.
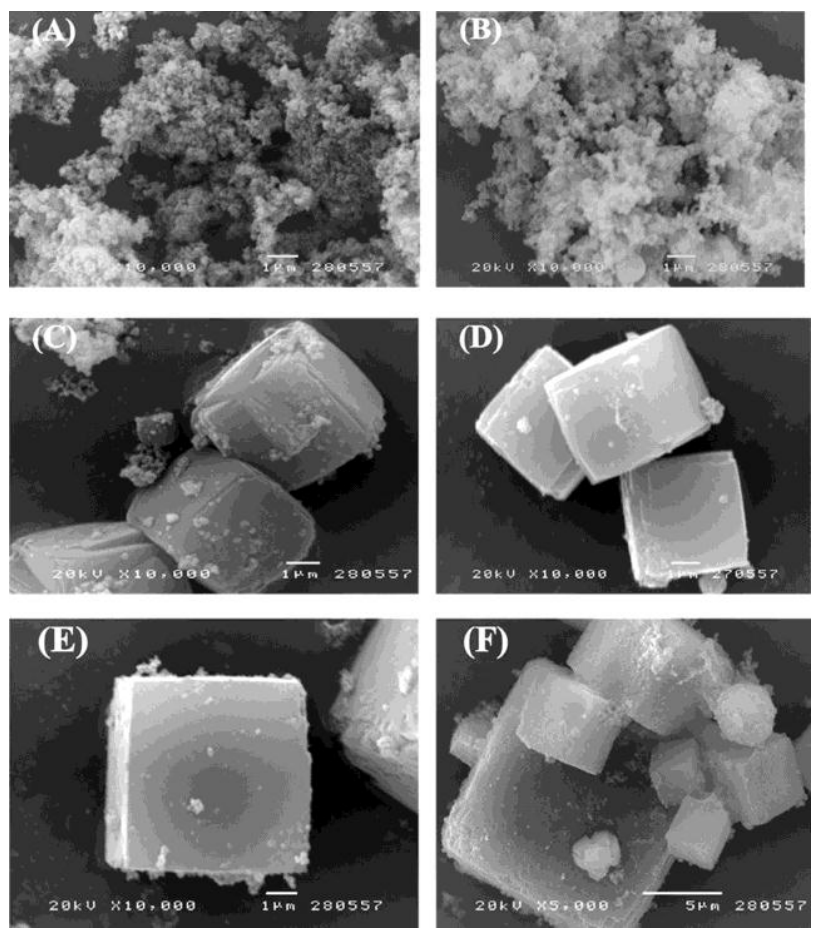

Figure 3 Scanning electron microscope (SEM) of $3 \mathrm{~A}$ zeolite from the fusion bagasse ash with potassium salts in the weight ratio of $1: 1.2$ at $550^{\circ} \mathrm{C}$ for $1 \mathrm{hr}$ (A), $2 \mathrm{hr}$ (B), $3 \mathrm{hr}$ (C), $4 \mathrm{hr}$ (D), $5 \mathrm{hr}$ (E) and $6 \mathrm{hr}$ (F).

The scanning electron microscope (SEM) of $3 \mathrm{~A}$ zeolite from the fusion bagasse ash with potassium salts in the weight ratio of $1: 1.2$ at $550{ }^{\circ} \mathrm{C}$ for various times can show as in Figure 3. The Figure $3 \mathrm{~A}-\mathrm{F}$ show the cubic shape of $3 \mathrm{~A}$ zeolite from the bagasse ash can indicated in reaction of 4-6 h.

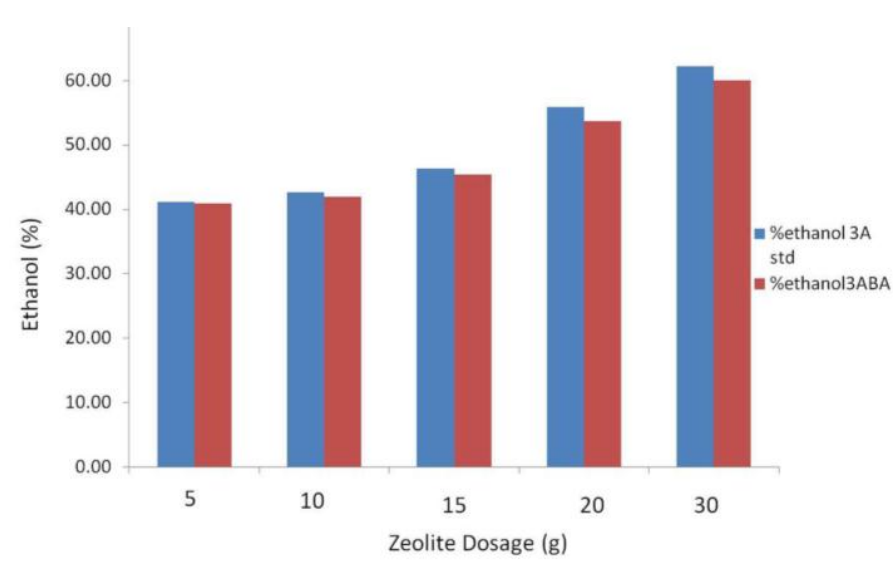

Figure 4 The Effect of 3A Zeolite dosage soaking on water-ethanol azeotropic concentration.

Figure 4 shows that effect of $3 \mathrm{~A}$ zeolite dosage soaking on water-ethanol azeotropic concentration. It shows that the high 3A zeolite standard and $3 \mathrm{~A}$ zeolite from bagasse ash of dosage will increase the ethanol concentration. The $30 \mathrm{~g}$ of zeolite $3 \mathrm{~A}$ were soaked in $50 \mathrm{~mL}$ of $40 \%$ water-ethanol azeotrope concentration for 60 minute is the optimum condition. This work indicated that the various adsorbents in azeotrope at 60 minute from $5 \mathrm{~g}$ to $30 \mathrm{~g}$, resulted in the alcohol concentration increase in the range of $40 \%$ to $61 \%$ (3A zeolite standard) and to $59 \%$ (3A zeolite from bagasse ash), respectively from the initial concentration. Water uptake was showed to be higher for 20 and 30 grams of $3 \mathrm{~A}$ zeolite for 60 minutes. The trend showed that slightly increasing trend with increasing $3 \mathrm{~A}$ zeolite dosage for the experiments.

\section{Conclusion}

3A Zeolite was able to synthesis from the bagasse ash by the fusion prior hydrothermal process. The optimum condition by fusion bagasse ash: potassium salt is $1: 1.2$ for $550{ }^{\circ} \mathrm{C}$ for 1 hour is the suitable condition. It was able to adsorb water from water-ethanol liquid mixture range of $40-61 \%$ for $3 \mathrm{~A}$ zeolite standard and $40-59 \%$ for $3 \mathrm{~A}$ zeolite from bagasse ash within 60 minutes of adsorption. 


\section{Acknowledgment}

This research was financially supported by The National Research Council and Thailand Institute of Scientific and Technological Research (TISTR). The authors would like to express gratitude to Environmental Pulp and Paper Co., Ltd for providing bagasse ash sample and Muang Thong Alumium Co., Ltd for providing aluminum sludge.

\section{References}

[1] N. Yalçin and H.J. Schenk, Ceramics International, vol. 27, Issue 2, pp. 219-224, 2001

[2] A. Jain, T.R. Rao, S.S. Sambi and P.D. Groover, Biomass Bioenergy, vol. 7, pp. 285-289, 1994.

[3] P.K. Bajpai and M.S. Rao, Ind. Eng. Chem. Prod. Res. Dev. 20, 1981.

[4] A.K. Dalal, M.S. Rao, Ind. Eng. Chem. Prod. Res. Dev. 24, 1985.

[5] H. Hamdan and Y.A. Keat, Malaysian patent NO. PI 9802741, 1993.

[6] D. Prasetyoko, Z. Ramli, S. Endud and H. Hamdan, Waste management, vol. 26, pp.1173, 2006

[7] W. Panpa and S. Jinawath, App. Cat.B: Env., vol. 90, pp. 389-94, 2009.

[8] N. Shigemoto, H. Hayashi and K. Miyaura, J. Mat. Sci., vol. 28, 1990.

[9] W.H. Shin and H.L. Chang, Material Letters, vol. 28, pp. 263, 1996.

[10] S. Rayalu, S.U. Meshram and M.Z. Hasan, J. Hazard. Mater, vol. 77, 2000.

[11] T. Wajima, M.Haga, K. Kuzawa, H. Ishimoto, O. Tamada, K. Itoc, T. Nishiyama, R.T. Downs and John F.Rakovane, J. Hazard. Mater, vol.132, 2006.

[12] M.R.El-Naggar, A.M. El-kamash, MI. El-Dessouky and A.K. Ghonaim, J. Hazard. Mater, vol. 154, 2008.

[13] C. Sathy, P.N. P, Micropor. Mesopor. Mater, vol. 108, 2008.

[14] H. Shigemoto, H. Hayashi and K. Miyaura, J. Mat. Sci, vol. 28, 1993.

[15] A. Rewadee, J.Balkus Jr. Kenneth, A. Suwimol, K. Pojanie. 2008. Micropor. Mesopor. Mater. 2008.

[16] A. Rewadee, A. Suwimol and K. Pojanie, "Synthesis of zeolite Na-A from two types of industrial wastes", The fifth International conferences on ISNEPP 2005, Bangkok, Thailand, pp. 1106-1113, Jan. 2005.

[17] W.K. Teo and D.M. Ruthven, "Adsorption of water from aqueous ethanol using 3A molecular sieve", Ind. Eng. Chem. Pro. Design and Development, vol. 25, Issue 1, pp. 17-21. , 1986.

[18] G. J. Elzbieta, P. Nastaj, Tabero and T. Aleksandrzak, "Experimental studies on $3 \mathrm{~A}$ and $4 \mathrm{~A}$ zeolite molecular sieve regeneration in TSA process: Aliphatic alcohol dewatering-water desorption", Chem. Eng. J., vol. 259, pp. 232-242, 2015. 